\title{
Endoplasmic reticulum stress-induced cell death mediated by the proteasome
}

\author{
L Egger, ${ }^{\star,}$, DT Madden ${ }^{1}$, C Rhême ${ }^{2}$, RV Rao ${ }^{1}$ and DE Bredesen ${ }^{1}$
}

\begin{abstract}
Cells exposed to sustained endoplasmic reticulum (ER) stress undergo programmed cell death and display features typical of apoptosis, such as cysteine aspartyl protease (caspase) activation, cytochrome $c$ release, and DNA fragmentation. Here, we show that the execution of cell death induced by ER stress is mediated via the proteasome. Inhibition of the proteasome by lactacystin prevented ER stress-induced degradation of Bcl-2, release of cytochrome $c$, processing of effector caspase-3, and exposure of phosphatidylserine. Owing to the ability of lactacystin to inhibit cytochrome $c$ release, we propose that the proapoptotic activity of the proteasome lies upstream of mitochondrial activation. Thus, the proteasome serves as a principal mediator of ER stress-induced cell death in this system.
\end{abstract}

Cell Death and Differentiation (2007) 14, 1172-1180. doi:10.1038/sj.cdd.4402125; published online 30 March 2007

The endoplasmic reticulum (ER) is the site of secretory protein synthesis, conformational maturation and quality control for correctly folded proteins. ER stress-inducing drugs disturb cellular homeostasis of protein production and lead to the accumulation of aberrant and unfolded proteins. ${ }^{1}$ Under normal conditions, proteins destined to be secreted or targeted to any of the compartments of the secretory pathway are passaged through the membrane via the Sec61 translocon and meet molecular chaperones, which ensure proper folding and assembly of proteins and protein complexes. ${ }^{2}$ Only proteins that achieve their native states are packaged into COPII vesicles for ER exit: proteins failing to adopt a stable conformation are dislocated through the Sec61 channel into the cytosol, where they are targeted for ubiquitylation and proteasomal degradation. ${ }^{3}$ Protein ubiquitylation is achieved via the sequential activity of three groups of enzymes: E1, E2, and E3. Mammalian cells have one E1 enzyme, which activates ubiquitin in an ATP-dependent manner and transfers it to one of at least 15 different E2 ubiquitin carriers, from which it is then transferred to one of the hundreds of E3 ubiquitin ligases present in the cell, the latter being responsible for substrate specificity. ${ }^{4}$ Proteasomal degradation of poorly folded ER-directed proteins is known as ER-associated degradation (ERAD), which is a cellular mechanism for achieving ER quality control. ${ }^{5}$ Homeostasis occurs so long as the load of newly synthesized proteins is matched by stochiometric molecular chaperone activity. Conditions that lead to the accumulation of unfolded proteins result in ER stress. When challenged with ER stress, cells can re-achieve homeostasis by initiating a series of orchestrated events known as the unfolded protein response (UPR) (for review see reference ${ }^{5}$ ). The key players of the UPR are three chronologically activated ER resident signaling proteins: PERK,
ATF6, and IRE1. Activation of these molecules results in the inhibition of translation (PERK), upregulation of molecular chaperones (ATF6), and upregulation of ERAD activity (IRE1) ${ }^{5,6}$ As a consequence, the ER experiences a reduction in protein folding burden while increasing folding and quality control capacity. If a cell fails to achieve homeostasis after fully activating the UPR and its associated ERAD activity, the cell initiates programmed cell death. ${ }^{7}$

ER stress-induced cell death has been the focus of many studies, but a detailed molecular description of this cell death pathway has yet to emerge. From previous reports, several pro-apoptotic factors and signaling pathways have been shown to be involved in ER stress-induced cell death, including calpain, Cysteine aspartyl protease (caspase-4) (human), caspase-12 (murine), CHOP/GADD153, TRAF2, ASK-1, JNK, and pro-apoptotic Bcl-2 family members, among others. ${ }^{7-10}$ In many instances, caspases have been implicated in this cell death pathway, on the grounds that broadspectrum caspase inhibitors block cell death. In some cases, however, cell death is not fully blocked by caspase inhibitors, suggesting that caspase-independent mechanisms may contribute to the execution of ER stress-induced cell death. Previously, it was shown that the serine protease inhibitor Pefabloc (AEBSF) could block ER stress-induced cell death, whereas the broad-spectrum caspase inhibitor, benzyloxycarbonyl-Val-Ala-Asp.fluoromethylketone (Z-VAD.fmk), could not, thus implicating the involvement of a serine protease (or other AEBSF-inhibitable activity) in caspase-independent ER stress-induced cell death. ${ }^{11}$

In this report, we show that the activity of the proteasome is necessary for ER stress-induced cell death. Proteasomal inhibition blocked ER stress-induced degradation of antiapoptotic Bcl-2 family proteins, cytochrome $c$ release,

\footnotetext{
${ }^{1}$ The Buck Institute for Age Research, Novato, USA and ${ }^{2}$ Division of Gastroenterology and Hepatology, University Hospital of Zürich, Zürich, Switzerland *Corresponding author: L Egger, The Buck Institute for Age Research, 8001 Redwood Blvd., CA 94945 Novato, USA. Tel: 4152092047 ; Fax: +1 415 209 2230; E-mail: lotti.egger@bluemail.ch

Keywords: apoptosis; proteasome; ER stress; lactacystin; cytochrome $C$

Abbreviations: BFA, brefeldin A; CHX, cycloheximide; caspase, cysteine aspartyl protease; GFPAn-V, His-GFP-Annexin-V; GFPu, GFP appended with the short degron, CL1; PI, propidium iodide; PS, phosphatidylserine; Q-VD-OPh, Q-Val-Asp-(non-O-methylated)-OPh; Z-VAD.fmk, benzyloxy-carbonyl-Val-Ala-Asp (O-methyl) fluoromethylketone; UPR, unfolded protein response

Received 16.8.06; revised 16.2.07; accepted 19.2.07; Edited by SH Kaufmann; published online 30.3.07
} 
caspase maturation, phosphatidylserine exposure, and cell death. Furthermore, cell lines harboring temperature-sensitive $\mathrm{E} 1$ ubiquitin-activating enzyme were protected from ER stress-induced programmed cell death at the restrictive temperature but not at the permissive temperature. From these results, we conclude that proteasomal activity lies upstream of mitochondria and cytochrome $c$ release in a pathway that links ER stress to cell death.

\section{Results}

Proteasomal inhibitors block ER stress-induced cell death induced by BFA and $\mathbf{C H X}$. To elicit robust cell death in response to ER stress, BFA-treated cells were coincubated with $\mathrm{CHX}$ so as to limit the activation of ATF6 and IRE1 translation-dependent survival pathways, as was done previously. ${ }^{8}$ We reported that ER stress-induced apoptosis was not prevented by caspase inhibition with Z-VAD.fmk but could be blocked by Pefabloc, a general inhibitor of serine protease activity. ${ }^{11}$ We therefore sought to identify the serine protease(s) responsible for cell death observed in our system. We used a mass spectrometry (MS) approach to identify proteins in cytosolic extracts bound to serine protease active site-directed inhibitors. Using two different serine protease inhibitors as bait, we repeatedly obtained hits for different proteasomal subunits in the inhibitor-enriched fractions from ER-stressed cells but did not detect any hits for ER-stress activated serine proteases (Supplementary Figure 1). Although the hits for proteasomal subunits were at the limit of significance, we tested the hypothesis that the proteasome might play a role in ER stress-induced cell death. To do so, we treated ER-stressed rat fibroblasts with several proteasomal inhibitors. Phase-contrast microscopy revealed that inhibition of the proteasome with either lactacystin, MG262, or epoxomycin, protected cells from ER stress (BFA/CHX, for $24 \mathrm{~h}$ ) to the same extent as Pefabloc (Figure 1a). As was previously shown, we saw that caspase inhibition with either Z-VAD.fmk or Q-Val-Asp-(nonO-methylated)-OPh (Q-VD-Oph) (Figure 1a and data not shown) did not prevent cells from undergoing ER stressinduced cell death, ${ }^{11}$ and $\mathrm{CHX}$ treatment alone did not induce cell death (Figure 1a).

Lactacystin and Pefabloc block degradation of a proteasomal substrate. We reasoned that if the protective effect of Pefabloc was due to proteasomal inhibition, then we should see an accumulation of proteasomal substrates when cells are treated with Pefabloc. One wellcharacterized substrate of the proteasome is GFPu , a fusion protein of GFP with a degron sequence, CL1. ${ }^{12,13} \mathrm{We}$ therefore transiently transfected rat fibroblasts with GFPu and followed green fluorescence by flow cytometry. Untreated cells have low levels of green fluorescence because $\mathrm{GFP}^{\mathrm{u}}$ is rapidly degraded by the proteasome. However, under conditions of proteasomal inhibition, as in the case of lactacystin treatment, GFP ${ }^{\mathrm{u}}$ significantly accumulated in cells (Figure 1b). GFP ${ }^{u}$ also accumulated in cells treated with Pefabloc (Figure 1b), demonstrating that Pefabloc can inhibit proteasomal activity in cells. This is consistent with previous finding that Pefabloc inhibits the trypsin-like activity of the proteasome in vitro. ${ }^{14,15}$

Proteasomal inhibitors block ER stress-induced phosphatidylserine exposure. To validate our phasecontrast study, we followed markers of programmed cell death, namely phosphatidylserine exposure before the loss of plasma membrane integrity. Cells exposing phosphatidylserine (an early marker of apoptosis) can be labeled with a His-GFP-Annexin-V (GFPAn-V) fusion protein, which binds to phosphatidylserine in a calcium-dependent manner. Loss of plasma membrane integrity can be followed by uptake of propidium iodide (PI), a cell non-permeating nuclear stain. Analysis by fluorescence microscopy showed that lactacystin and Pefabloc, but not Z-VAD.fmk, prevented the exposure of phosphatidylserine provoked by ER stress with BFA $(5 \mu \mathrm{g} / \mathrm{ml})$ and $\mathrm{CHX}(10 \mu \mathrm{g} / \mathrm{ml})$ for $24 \mathrm{~h}$ (Figure 2a). These observations were quantified by flow cytometry of GFPAn-V/PI-stained cells. After $22 \mathrm{~h}$ of ER stress, fluorescence-activated cell-sorting analysis revealed that $63 \%$ of the stressed cells were GFPAnV-positive, compared to $13 \%$ in non-stressed cells (Figure $2 b$ ). Treatment with lactacystin or Pefabloc significantly protected cells from ER stress-induced cell death, reducing the number of GFPAn-V positive cells to that seen in untreated cells $(P<0.001$; BFA $/ \mathrm{CHX}$ versus $\mathrm{BFA} / \mathrm{CHX}+$ Pefabloc or $\mathrm{BFA} /$ $\mathrm{CHX}$ + lactacystin), whereas Z-VAD.fmk treatment only partially blocked ER stress-induced cell death (Figure 2c). The capacity of lactacystin and Pefabloc to protect cells from ER stress was not unique to BFA/CHX, as cell death induced by thapsigargin/ $\mathrm{CHX}$ and tunicamycin/ $\mathrm{CHX}$ was also blocked by these proteasomal inhibitors (Figure $2 e$ and $\mathrm{f}$, respectively). We could also show that in the absence of CHX, BFA killed cells in a proteasome-dependent manner (Figure 2d)

Lack of a functional E1 ubiquitin-activating enzyme delays ER stress-induced cell death. We tested the extent to which a cell line harboring a temperature-sensitive mutation in the E1 ubiquitin-activating enzyme would be protected from ER stress-induced cell death at the nonpermissive temperature. Upon induction of ER stress with BFA and $\mathrm{CHX}$, we quantified the fraction of GFPAn-V positive cells in ts20, a mutant cell line harboring a temperature-sensitive allele of the E1 ubiquitin-activating enzyme, as well as $\mathrm{H} 38-5$, a ts20 derivative in which the $\mathrm{E} 1$ ubiquitin-activating enzyme has been restored (Figure $3 \mathrm{a}$ ). After $30 \mathrm{~h}$ of treatment with BFA $(10 \mu \mathrm{g} / \mathrm{ml})$ and $\mathrm{CHX}(10$ $\mu \mathrm{g} / \mathrm{ml})$ at the permissive temperature $\left(34^{\circ} \mathrm{C}\right)$, both $\mathrm{H} 38-5$ and ts20 lines were effectively killed (Figure 3a). Cell death is reported as the fold-induction because the ts20 line has a greater background level of cell death than does the H38-5 line. (For raw data, see Supplementary Figure 2a.) However, at the non-permissive temperature, only the E1-restored H38-5 cells responded to BFA/CHX, whereas the ts20 cell line did not (Figure $3 \mathrm{a}$ ). We extended these findings by testing whether ER stress-induced cell death elicited by thapsigargin and tunicamycin would also require a functional E1 ubiquitin activating enzyme activity (Figure 3b, data are normalized as in Figure 3a. For raw data, see Supplementary Figure $2 b$ ). For each BFA, thapsigargin, and tunicamycin, cells were killed in both cell lines at $34^{\circ} \mathrm{C}$ and in the H38-5 
a

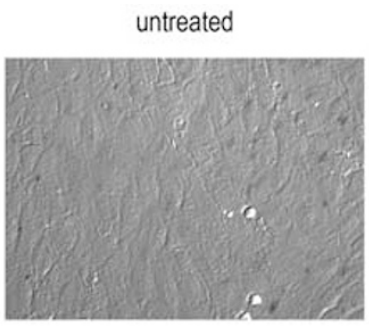

BFA $C H X+$ Pefabloc

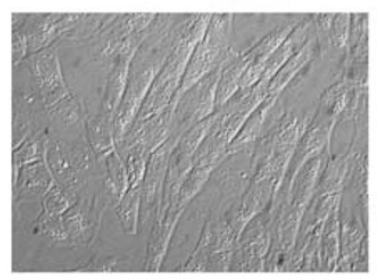

BFA/CHX+Z-VAD.fmk
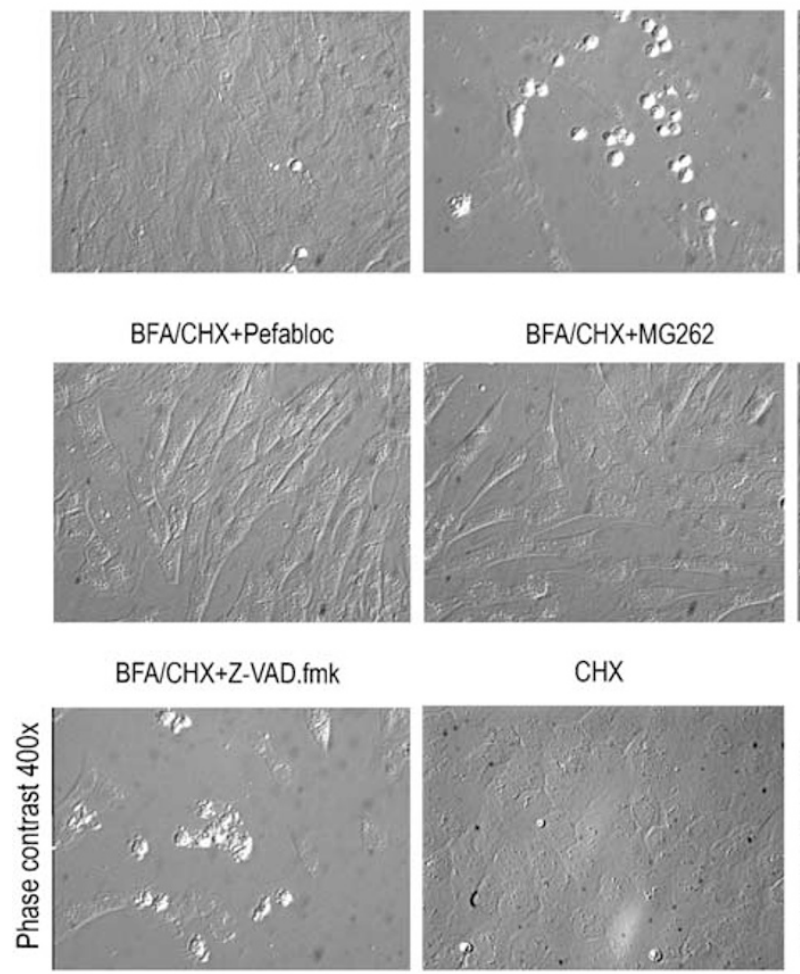

$\mathrm{BFA} / \mathrm{CHX}+\mathrm{MG} 262$

$\mathrm{CHX}$

b

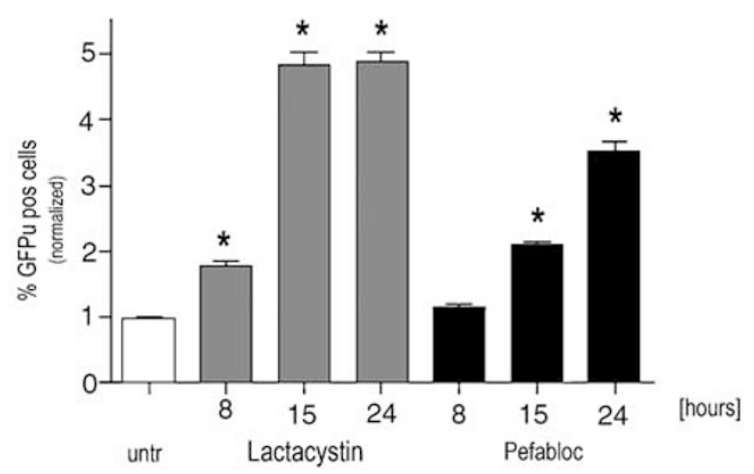

BFA/CHX+Lactacystin

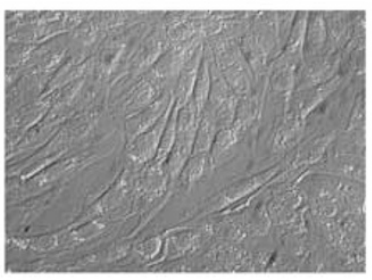

BFA/CHX+Epoxomycin
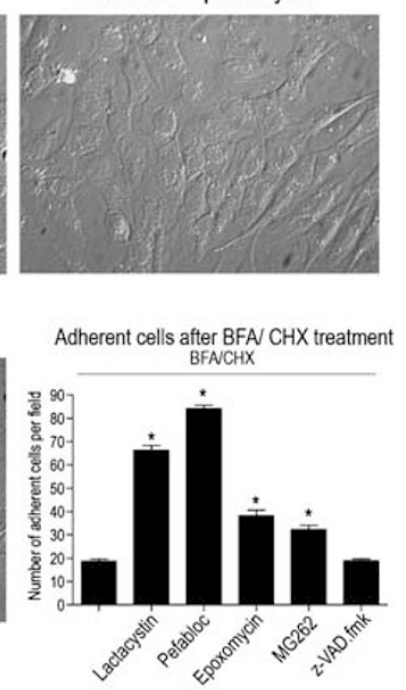

Figure 1 Cell survival of ER-stressed cells by proteasomal inhibition. (a) Phase-contrast microscopy ( $\times 400$ magnification) of rat fibroblasts grown to confluence and left either untreated or exposed to ER stress with BFA $(5 \mu \mathrm{g} / \mathrm{ml})$ and $\mathrm{CHX}(10 \mu \mathrm{g} / \mathrm{ml})$ or treated with $\mathrm{CHX}$ alone for $24 \mathrm{~h}$. Cells were pretreated either with lactacystin $(5 \mu \mathrm{M})$, Pefabloc $(300 \mu \mathrm{M})$, MG262 (100 nM), epoxomycin (100 nM), or Z-VAD.fmk (100 $\mu \mathrm{M}), 30$ min before cell stress. Graph: adherent cells were counted from 10 randomly chosen fields for BFA/CHX treated samples (bar graph, error bars correspond to S.E.M. ${ }^{*} P<0.001 \mathrm{BFA} / \mathrm{CHX}$ alone versus $\mathrm{BFA} / \mathrm{CHX}$ with indicated inhibitors). (b) Accumulation of green fluorescence in cells transiently transfected with GFP" ${ }^{u}$. Fold increase of GFP ${ }^{\mathrm{u}}$ fluorescence after 8,15 , or $24 \mathrm{~h}(N=6,9$, or 10 , respectively) of treatment with lactacystin $(5 \mu \mathrm{M})$ or Pefabloc $(300 \mu \mathrm{M})$ compared to untreated cells $(N=11)$. Error bars correspond to S.E.M. ${ }^{*} P<0.001$ treated versus untreated

line at $40^{\circ} \mathrm{C}$. However, ts 20 cells incubated at $40^{\circ} \mathrm{C}$ did not induce cell death triggered by BFA, thapsigargin, and tunicamycin. From these results, we conclude that ER stress-induced cell death is strictly dependent on a functional E1 ubiquitin-activating enzyme activity.

\section{Proteasomal activation lies upstream of mitochondrial} outer-membrane permeabilization and caspase processing. Having shown that proteasomal activity is necessary for ER stress-induced cell death, we wished to place the proteasome within the biochemical pathway that connects a stressed ER to the cell death machinery. To find out, we began by testing whether the activity of the proteasome lies upstream of effector caspase processing. Upon stimulation of cells with BFA/CHX, we detected a dramatic reduction in the $32 \mathrm{kDa}$ procaspase- 3 and a corresponding increase in the $17 \mathrm{kDa}$ active fragment (Figure 4a). In the presence of lactacystin, we found that procaspase- 3 was not processed to the same extent as that seen for $\mathrm{BFA} / \mathrm{CHX}$ alone. Proteasomal inhibition with Pefabloc, on the other hand, afforded a more complete block of caspase-3 maturation. Furthermore, we found that 

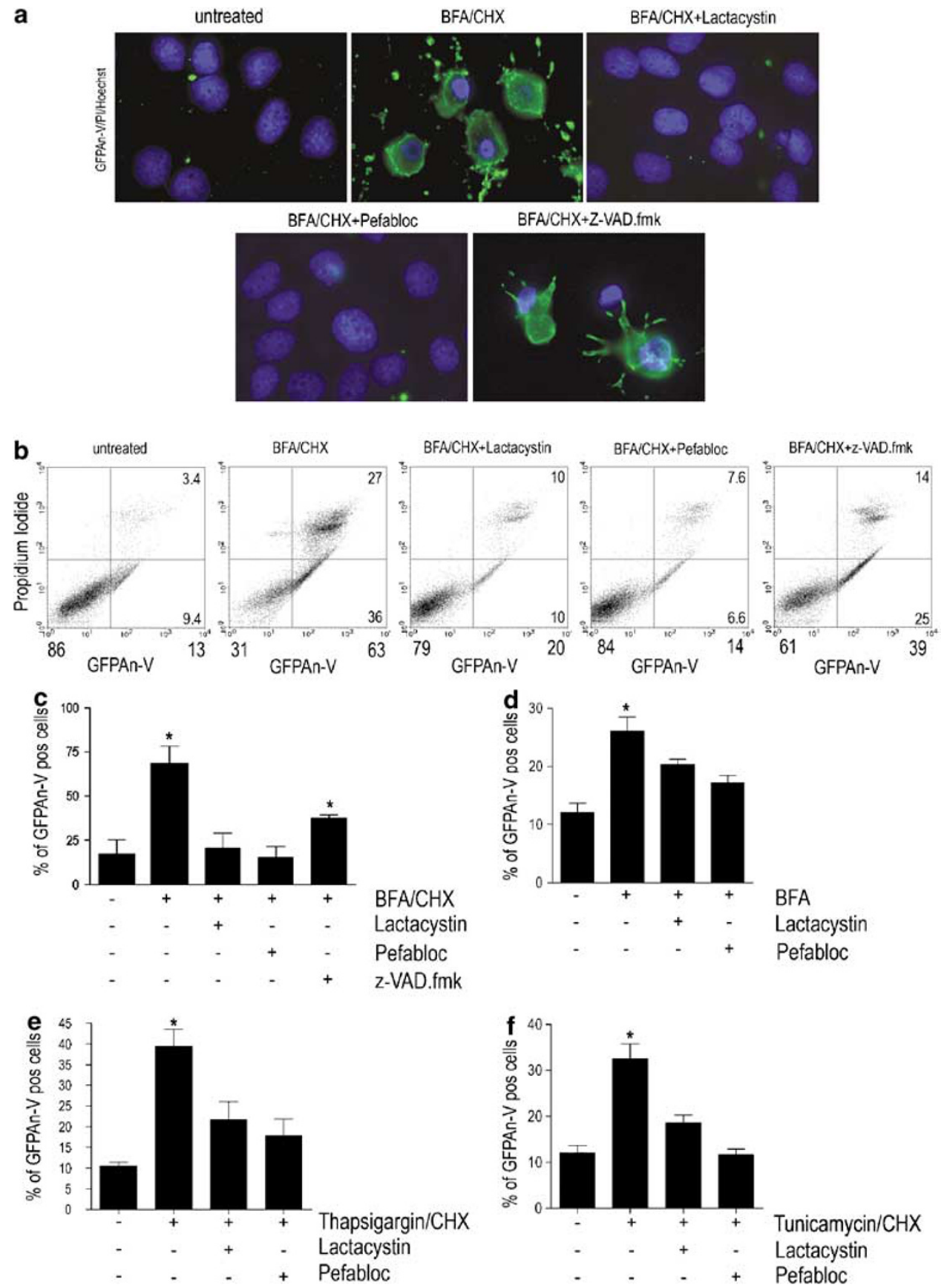

Figure 2 Inhibition of ER stress-induced exposure of PS by proteasomal inhibition. Rat fibroblasts were grown to confluence and left either untreated or exposed to ER stress. Cells were pretreated either with lactacystin $(5 \mu \mathrm{M})$, Pefabloc $(300 \mu \mathrm{M})$, or Z-VAD.fmk (100 $\mu \mathrm{M})$, 30 min before cell stress. (a) GFPAn-V-, Pl-, and Hoechst 33342stained cells were visualized by fluorescence microscopy after $24 \mathrm{~h}$ treatment with BFA $(5 \mu \mathrm{g} / \mathrm{ml}) \mathrm{CHX}(10 \mu \mathrm{g} / \mathrm{ml})$. (b) Representative flow cytometry dot plots from rat fibroblasts stained with GFPAn-V/PI after $22 \mathrm{~h}$ of ER stress. The average cell counts are listed in each dot-plot quadrant and are expressed as a percentage. (c) Statistical evaluation of apoptotic cells (GFPAn-V positive): Untreated $(N=34)$, treated with BFA/CHX $(N=17)$, or stressed and pretreated with either lactacystin $(N=16)$, Pefabloc $(N=17)$, or Z-VAD.fmk $(N=9) 30$ min before cell stress. Error bars correspond to S.E.M. ${ }^{*} P<0.001$ treated versus untreated group. (d-f) Statistical evaluation of apoptotic cells (GFPAn-V positive) after ER stress with BFA $(10 \mu \mathrm{g} / \mathrm{ml})$ alone $(72 \mathrm{~h}, \mathrm{~d})$, thapsigargin/CHX $(24 \mathrm{~h}, \mathbf{e})$, or tunicamycin/CHX (48 h, f) and pretreated with either lactacystin or Pefabloc, 30 min before cell stress. Data were collected from three independent experiments. Error bars correspond to S.E.M. ${ }^{*} P<0.001$ treated versus untreated group

Z-VAD.fmk and Q-VD-OPh did not impose a complete block in ER stress-induced cell death (Figures 1 and 2, Ref. ${ }^{11}$ and data not shown). This suggests that some fraction of the caspase-3 processing associated with $\mathrm{BFA} / \mathrm{CHX}$ treatment might only be an epiphenomenon, and is not a key player in this pathway. Nevertheless, the fact that both lactacystin and Pefabloc decreased ER stress-induced caspase-3 maturation indicated that the proteasome lies upstream of caspase-3 processing. Moreover, we saw a similar processing pattern for caspase-2 (Supplementary 

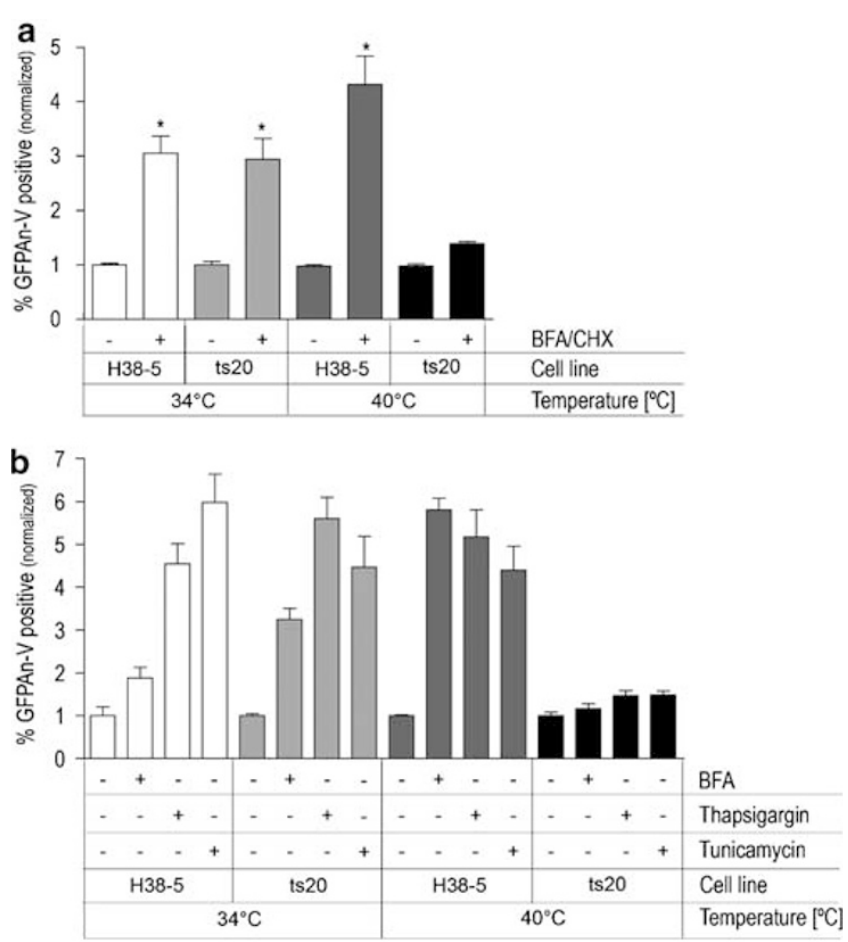

Figure 3 ER stress-induced cell death is delayed in E1-deficient cells. (a) Two cell lines, ts20 and H38-5, were treated for $30 \mathrm{~h}$ with BFA $(10 \mu \mathrm{g} / \mathrm{ml})$ and $\mathrm{CHX}$ $(10 \mu \mathrm{g} / \mathrm{ml})$. The ts 20 cell line carries a temperature-sensitive E1 enzyme, whereas the H38-5 cell line is a derivative of the ts20 line in which E1 activity has been restored. Plots show the fold increase of GFPAn-V cells (determined by flow cytometry) normalized to the untreated condition in each case. $\mathrm{H} 38-5,34^{\circ} \mathrm{C}$ : $(N=25)$, ts $20,34^{\circ} \mathrm{C}:(N=24), \mathrm{H} 38-5,40^{\circ} \mathrm{C}:(N=15)$, ts $20,40^{\circ} \mathrm{C}:(N=21)$, error bars correspond to S.E.M., ${ }^{\star} P<0.001$ for treated versus the corresponding untreated control. (b) Cells were treated for $36 \mathrm{~h}$ with BFA $(1 \mu \mathrm{g} / \mathrm{ml})$, thapsigargin $(100 \mathrm{nM})$, or tunicamycin $(0.5 \mu \mathrm{g} / \mathrm{ml})$, and the fraction of GFPAn-V-positive cells were determined by flow cytometry as in (a). For raw data see Supplementary Figure 2. Data were collected from three independent experiments, error bars correspond to S.E.M.

Figure 3), placing this caspase downstream of the proteasome as well.

We previously showed in our model of ER stress-induced cell death using the BFA/CHX cocktail that over expression of $\mathrm{Bcl}-2$ was protective, indicating mitochondrial involvement in this pathway. Furthermore, BFA/CHX treatment resulted in cytochrome $c$ release from mitochondria (Figure $4 \mathrm{~b}$, and Ref $\left.{ }^{11}\right)$. Thus, we asked the question whether the deathinducing activity of the proteasome could affect the outermembrane permeability of the mitochondria. With the proteasome inhibitors lactacystin and Pefabloc, we followed the BFA/CHX-induced change in localization of cytochrome $c$ from mitochondrial-associated punctate structures (Figure $4 \mathrm{~b}$ ) to a diffuse pattern. At $5 \mu \mathrm{M}$, lactacystin blocked the release of cytochrome $c$ from mitochondria to the same extent as Pefabloc $(300 \mu \mathrm{M})$, whereas Z-VAD.fmk $(100 \mu \mathrm{M})$ had no effect. When co-stained with Hoechst 33342, cells with cytosolic cytochrome $c$ also had condensed and fragmented nuclei typical of apoptotic cells. In contrast, the nuclei of untreated cells or stressed cells treated with either Pefabloc or lactacystin were normal in appearance (Figure 4b).
The fact that proteasome inhibitors prevented the release of cytochrome $c$ from mitochondria in response to ER stress indicated that the death-promoting activity of the proteasome lies upstream of mitochondrial outer-membrane permeabilization. The Bcl-2 family members are the key regulators of mitochondrial outer-membrane permeabilization. We therefore expanded our search of proteasome-regulated apoptotic events to include Bcl-2 family members because it seemed plausible that in reponse to prolonged ER stress, the proteasome could function to degrade anti-apoptotic Bcl-2 family members. This would tip the balance of pro-apoptotic versus anti-apoptotic Bcl-2 family members towards programmed cell death. To test the possibility that proteasomal activity could cause degradation of anti-apoptotic Bcl-2 family members in response to ER stress, we followed the expression levels of $\mathrm{Bcl}-2, \mathrm{Bcl}-\mathrm{w}$, and $\mathrm{Bcl}-\mathrm{xL}$ by Western blot analysis. After treating cells for $24 \mathrm{~h}$ with BFA/CHX, we observed a dramatic reduction in $\mathrm{Bcl}-2, \mathrm{Bcl}-\mathrm{w}$, and $\mathrm{Bcl}-\mathrm{xL}$ protein levels. What is more, the reduced abundance of these proteins was reversed by proteasomal inhibition with lactacystin and pefabloc (Figure 4c). This effect did not require $\mathrm{CHX}$ in the experiment because extracts prepared from cells treated with BFA alone showed that $\mathrm{Bcl}-2$ was degraded after $72 \mathrm{~h}$ of $\mathrm{ER}$ stress in a proteasome-dependent manner (Figure 4c). Whereas we did observe a loss of the full-length Mcl-1 during conditions of ER stress, we did not see an accumulation of this species when proteasomal inhibitors were included (data not shown).

\section{Discussion}

In the present study, we demonstrate a requirement for the proteasome in ER stress-induced cell death. We determined that the pro-apoptotic activity of the proteasome lies in a pathway upstream of $\mathrm{Bcl}-2, \mathrm{Bcl}-\mathrm{w}$, and $\mathrm{Bcl}-\mathrm{xL}$ degradation, mitochondrial release of cytochrome $c$, caspase-3 maturation, and phosphatidylserine exposure. In each case, the proteasome inhibitors lactacystin and Pefabloc are effective at blocking these markers of a pathway that connects protracted ER stress to cellular destruction. As further indication that the proteasome is a player in this pathway, we utilized a mutant cell line that harbors a temperature-sensitive allele of the E1 ubiquitin-activating enzyme. ER stress-induced cell death proceeded normally at the permissive temperature, but was blocked at the restrictive temperature, indicating that one of the functions of the ubiquitin proteasome system is to initiate a pro-apoptotic signaling cascade in response to prolonged ER stress.

Previously, ER stress-induced apoptosis was shown to be mediated by a serine protease-like activity that was blocked by Pefabloc, a general inhibitor of serine proteases. ${ }^{11} \mathrm{We}$ therefore sought to elucidate the identity of the Pefablocinhibitable activity required for ER stress-induced cell death. Toward this end, we developed two affinity labeling methods, one with biotinylated and the other with fluorogenic active sitedirected serine protease inhibitors and subsequently analyzed the samples by mass spectrometry (Supplementary Figure 1). Although we were unable to identify any serine proteases in either approach, we repeatedly obtained hits for proteasomal subunits among the proteins found both in the 
a
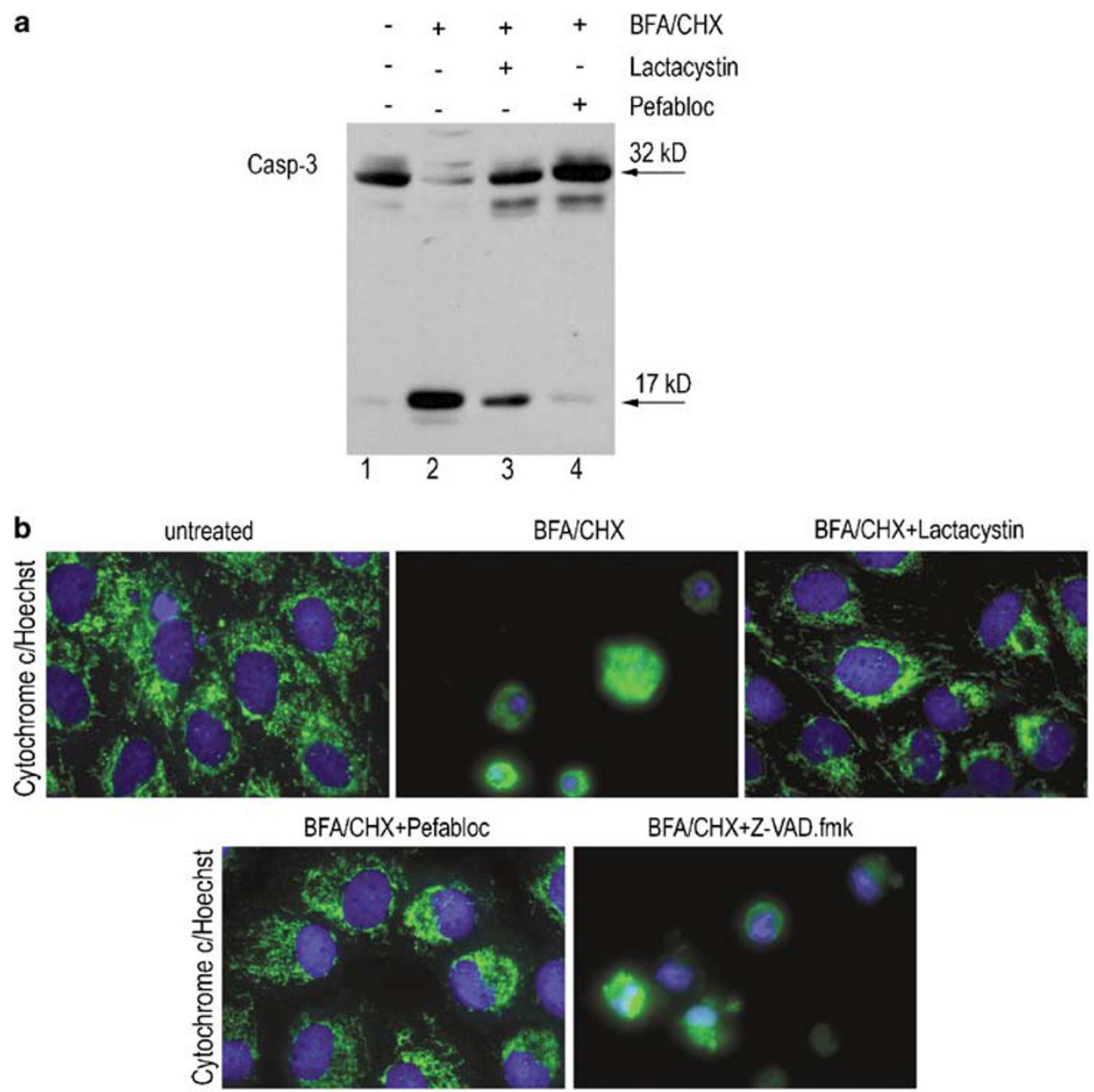

c

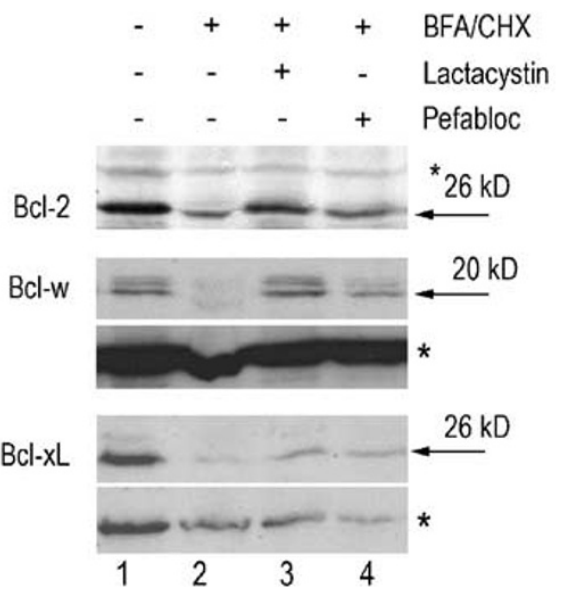

$\mathrm{Bcl}-2$

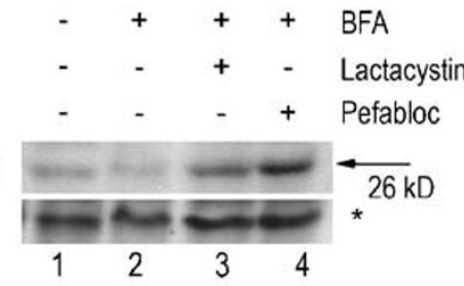

Figure 4 Proteasomal inhibitors block ER stress-induced caspase-3 processing, cytochrome c release, and degradation of antiapoptotic Bcl-2 family proteins. (a) Western blot showing pro- (p32) and processed- (p17) forms of caspase-3, in either untreated, treated with BFA (5 $\mu \mathrm{g} / \mathrm{ml})$ and CHX (10 $\mu \mathrm{g} / \mathrm{ml})$ for $24 \mathrm{~h}$, or co-treated with either lactacystin $(5 \mu \mathrm{M})$, or Pefabloc $(300 \mu \mathrm{M})$. (b) Anti-cytochrome $c$ immunocytochemistry and Hoechst 33342 stain of ER-stressed rat fibroblasts treated with BFA (5 $\mu \mathrm{g} / \mathrm{ml})$ and $\mathrm{CHX}(10 \mu \mathrm{g} / \mathrm{ml})$ for $22 \mathrm{~h}$. Cells were preincubated either with lactacystin $(5 \mu \mathrm{M})$, Pefabloc $(300 \mu \mathrm{M})$, or Z-VAD.fmk $(100 \mu \mathrm{M}) 30$ min before cell stress. (c) Western blot showing the levels of Bcl-2, Bcl-w, and Bcl-XL, in either untreated, treated with BFA $(5 \mu \mathrm{g} / \mathrm{ml})$ and $\mathrm{CHX}(10 \mu \mathrm{g} / \mathrm{ml})$ for $24 \mathrm{~h}$, or treated with either lactacystin $(5 \mu \mathrm{M})$, or Pefabloc $(300 \mu \mathrm{M})$. Western blot showing Bcl-2 levels after BFA $(10 \mu \mathrm{g} / \mathrm{ml})$ treatment alone for $72 \mathrm{~h}$ with the same inhibitors. Unspecific bands from the same gel are shown as loading controls. Asterisks $\left({ }^{*}\right)$ mark the position of non-specific bands recognized by the antibody, which serve as loading controls. Arrows point to the position of molecular weight markers at the size indicated 


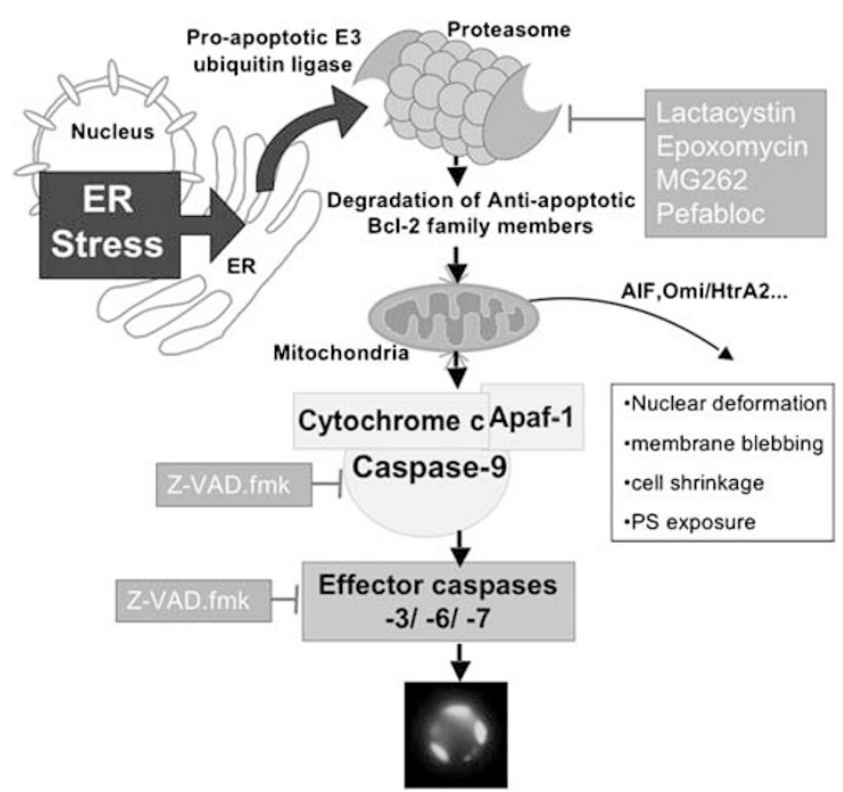

Figure 5 Putative model of proteasome-mediated ER stress-induced cell death. ER stress activates a pro-apoptotic ER ubiquitin ligase which tags anti-apoptotic $\mathrm{Bcl}-2$ family members with ubiquitin. Subsequently, the proteasome degrades these anti-apoptotic molecules, thereby tipping the balance between pro-and antiapoptotic factors towards apoptosis. Subsequently, mitochondria are activated, and pro-apoptotic factors such as cytochrome $c$, AIF, Omi, and others are released. As a result, caspase-dependent and independent signaling cascades ensue, eventually leading to cell death. Inhibition of proteasomal activity with lactacystin, epoxomycin, MG262, or Pefabloc prevents the degradation of anti-apoptotic factors, and therefore protect the cells from ER stress-induced cell death

biotinylated inhibitor-enriched fraction as well as those that were labeled by the fluorogenic active site-directed serine protease inhibitor, albeit near the limit of detection in both cases. That the proteaseome, a threonine protease, could be identified in our mass spectrometry approaches with serine protease inhibitors serving as bait is not surprising because several serine protease inhibitors, among them Pefabloc, have been shown to inhibit the proteasome non-selectively. ${ }^{14,15}$ Whereas it was previously proposed that the inhibitory effect of Pefabloc on ER stress-induced cell death was due to inhibition of a serine protease, ${ }^{11}$ we now believe that at the concentrations used $(300 \mu \mathrm{M})$, Pefabloc inhibits the activity of the proteasome, and that proteasomal inhibition prevents cells from undergoing apoptosis in response to ER stress. This hypothesis is supported by the fact that Pefabloc treatment results in an accumulation of an engineered proteasomal substrate, GFP ${ }^{u}$. However, we cannot exclude the possibility that additional Pefabloc-inhibitable serine protease activities might also play a role in the novel ER stress-induced apoptotic cascade described herein.

To date, the mediators that link ER stress to the apoptotic machinery have not been fully elucidated. Caspase-12 was proposed to function as the apical caspase responsible for initiating an apoptotic cascade in response to ER stress. However, caspase-12 $2^{-1-}$ mouse embryonic fibroblasts (MEFs) were shown to be only partially protected from ER stress-inducing agents. ${ }^{16}$ Furthermore, caspase-12 processing was shown to be downstream of the Bax/Bak gateway, as indicated by the fact that maturation of caspase-12 was blocked when Bax/Bak double knockout MEFs were treated with BFA. ${ }^{9}$ These findings make it unlikely that caspase- 12 could be a principal mediator of ER stress-induced cell death. CHOP/GADD153, the pro-apoptotic translational-dependent mediator of ER stress-induced cell death, ${ }^{17}$ is not a player in our model system because we co-treated cells with $\mathrm{CHX}$ so as to bypass the expression of protective UPR genes, as was done previously. ${ }^{8,11}$ Therefore, we have defined an ER stressinduced cell death pathway that is independent of $\mathrm{CHOP} /$ GADD153. We also excluded calpains from playing a role in this paradigm because none of the calpain inhibitors tested had any protective effect on ER stress-induced apoptosis (data not shown).

Our finding that the proteasome is a mediator of ER stressinduced cell death is surprising because many reports document that proteasome inhibitors alone are toxic, ${ }^{18,19}$ and toxicity is exacerbated when cells also experience ER stress. ${ }^{20}$ What is more, proteasomal inhibitors can actually cause ER stress, as shown by the upregulation of Grp78/Bip and CHOP/GADD153, thus providing further evidence that proteasomal activity is intimately coupled to ERAD as the last leg of the UPR. ${ }^{21,22}$ Recently, a potent proteasome inhibitor, PS-341 (Bortezomib), was shown to be effective in the treatment of multiple myeloma, and is now approved by the US Food and Drug Administration. The toxicity of PS-341 in multiple myeloma cells is very likely to be the result of ER stress-induced apoptosis. ${ }^{22}$

Pro-apoptotic functions of the proteasome have been described in several instances including the constitutive death of neutrophils as well as NGF withdrawal, DNA damage, glucocorticoid treatment and reduced extracellular potassium. ${ }^{23-27}$ Additionally, the proteasome has been implicated in the early stages of wallerian degeneration after axotomy. ${ }^{28}$ In response to DNA damage, the large Bcl-2 homology domain-only protein Mule/ARF-BP1 was shown to ubiquitylate $\mathrm{Mcl}-1$ - an anti-apoptotic Bcl-2 family member - thereby causing its degradation via the proteasome. ${ }^{29}$ Also, the $\mathrm{Bcl}-2$ family members $\mathrm{Bcl}-2, \mathrm{Mcl}-1$, and $\mathrm{Bfl}-1$ have been shown to undergo proteasomal degradation when critical serine or threonine residues become dephosphorylated in response to treatment with paclitaxel or TNF. ${ }^{30-35}$ In these examples, proteasomal activity tips the balance of pro- and anti-apoptotic $\mathrm{Bcl}-2$ family members toward apoptosis, and thereby serves as a mediator of apoptosis.

The induction of UPR and ERAD in response to ER stress is protective. But at some point, after failing to achieve cellular homeostasis, cells induce programmed cell death. The mechanism of this switch is not fully understood, but likely involves the expression of CHOP/GADD153, which can cause downregulation of $\mathrm{Bcl}-2 .^{36}$ However, even under translation-inhibitory conditions, where CHOP/GADD153 is not expressed, we find that proteasomal activity is required for ER stress-induced cell death. Despite the fact that the prosurvival function of ERAD requires proteasomal activity, it seems that the later pro-apoptotic arm of ER stress also requires the activity of the proteasome. Therefore, the proteasome is involved both in protecting cells from ER stress (as in the case of ERAD) and in the activation of programmed cell death. We have speculated that these two opposing 
activities of the proteasome could be the result of the alternative regulation of multiple E3 ubiquitin-ligase activities. In the protective phase of ER stress (UPR and ERAD), the E3 ubiquitin ligases $\mathrm{SCF}^{\mathrm{FBS} 1}$ and $\mathrm{SCF}^{\mathrm{FBS} 2}$ recognize misfolded proteins that have been dislocated from the $E R$, thereby directing the proteasome to degrade these malfolded - and potentially toxic-proteins. ${ }^{5}$ Later, the cell could commit to cell death by upregulating an E3 ubiquitin-ligase activity that may target an anti-apoptotic molecule, such as the anti-apoptotic molecules Bcl-2, Bcl-w, and Bcl-xL. One candidate for such an activity is Mule/ARF-BP1, which has been shown to ubiquitylate $\mathrm{Mcl}-1$, thus tagging $\mathrm{Mcl}-1$ for proteasomal degradation and tipping the balance toward apoptosis. ${ }^{29}$ However, we did not find that full-length $\mathrm{Mcl}-1$ accumulates in the presence of proteasomal inhibitors (data not shown). Therefore, the putative ER stress-activated E3 ubiquitin-ligase activity is not likely to be Mule/ARF-BP1 (Figure 5).

Manipulation of the cell's decision to induce cell death in response to protracted ER stress may be possible with the development of specific E3 ubiquitin ligase inhibitors: Those that would inhibit $\mathrm{SCF}^{\mathrm{FBS} 1}$ and $\mathrm{SCF}^{\mathrm{FBS} 2}$ would be toxic, whereas those that would inhibit pro-apoptotic E3 ubiquitin ligases - like Mule/ARF-BP1 - would be protective. As evidence has emerged that ER stress plays a role in neurodegenerative diseases like Alzheimer's, Huntington's, Parkinson's and ALS, ${ }^{37}$ reagents that block the proteasomal degradation of anti-apoptotic molecules may prove to be neuroprotective.

\section{Materials and Methods}

Cells and drug treatments. Rat 6 embryo fibroblasts (R6) were cultured in DMEM with $5 \%$ FCS, $1000 \mathrm{mg} / /$ glucose, $60 \mu \mathrm{g} / \mathrm{ml}$ penicillin, and $100 \mu \mathrm{g} / \mathrm{m}$ streptomycin (Mediatech, Inc. Herndon, US). The temperature-sensitive ts20 Balb/C 3 T 3 clone A31 fibroblast cell line and its $\mathrm{E} 1$ corrected $\mathrm{H} 38-5$ derivative were cultured in DMEM with $10 \% \mathrm{FCS}, 4500 \mathrm{mg} / \mathrm{l}$ glucose, $60 \mu \mathrm{g} / \mathrm{ml}$ penicillin, and $100 \mu \mathrm{g} / \mathrm{ml}$ streptomycin. ${ }^{38} \mathrm{Cells}$ were maintained at $34^{\circ} \mathrm{C}$. Where indicated, they were shifted to $40^{\circ} \mathrm{C}$ for $30 \mathrm{~h}$ before treatment with brefeldin $\mathrm{A}(\mathrm{BFA})$, or $36 \mathrm{~h}$ for treatment with tunicamycin or thapsigargin, with or without cycloheximide (CHX). Where indicated, cells were pre-incubated with $100 \mu \mathrm{M}$ Z-VAD.fmk (MP Biomedicals, OH, US), 150$300 \mu \mathrm{M}$ Pefabloc (AEBSF; Roche Diagnostics; Mannheim; Germany), $50 \mathrm{nM}-5 \mu \mathrm{M}$ lactacystin (Calbiochem, Darmstadt, Germany), $100 \mathrm{nM}$ epoxomycin (EMD Bioscience, San Diego, USA), or $100 \mathrm{nM}$ Z-Leu-Leu-Leu-B(OH) ${ }_{2}$ (MG262; Biomol, USA) for $30 \mathrm{~min}$ before adding $5-10 \mu \mathrm{g} / \mathrm{ml} \mathrm{BFA}$ and $/$ or $10 \mu \mathrm{g} / \mathrm{ml} \mathrm{CHX}$ alone (both drugs: Sigma, St Louis, MO, USA).

Counting of viable cells. Adherent cells from 10 randomly chosen fields $(\times 400$ of magnification) were counted after $24 \mathrm{~h}$ of treatment with BFA/CHX in the absence or presence of inhibitors.

Preparation of cytosol. Stressed or non-stressed monolayer cells were scraped from $100 \mathrm{~mm}$ plates, washed in PBS and lysed by 3-4 cycles of freezethawing in buffer A (25 mM Hepes, pH 7.4, 2 mM EGTA, $2 \mathrm{mM} \mathrm{MgCl}$, 2 mM DTT $100 \mu \mathrm{M}$ PMSF, $10 \mu \mathrm{g} / \mathrm{ml}$ leupeptin, $400 \mathrm{ng} / \mathrm{ml}$ pepstatin, $10 \mu \mathrm{g} / \mathrm{ml}$ aprotinin, $5 \mu \mathrm{g} / \mathrm{ml}$ cytochalasin B). The homogenate was centrifuged at $100000 \times \mathrm{g}$ and the supernatant was used for Western blotting.

Preparation of total protein extracts. Media from stressed or nonstressed monolayer cells were collected and combined with the cells after trypsinization. After pelleting, cells were re-suspended in RIPA buffer $(50 \mathrm{mM}$ Tris, pH 7.5, 0.5\% deoxycholate, $1 \%$ Triton X-100, 0.1\% SDS, $150 \mathrm{mM} \mathrm{NaCl}$ ) containing protease inhibitors (complete, Mini; Roche; Penzberg; Germany). Extracts were used for Western blotting.
SDS-PAGE and Western blotting. Cytosol (40-50 $\mu \mathrm{g})$ or total extracts were run on $10-20 \%$ SDS-PAGE, transferred to Nitrocellulose (Whatman; NJ; US) and immunodetected by anti-caspase-3 (Cell Signaling; Danvers; US), anti-Bcl-2, or anti-Bcl-xL (BD Biosciences, San Jose, CA, USA), anti-Bcl-w, or anti-caspase-2 (a kind gift from Andreas Strasser; WEHI; Melbourne, Australia), with primary antibodies followed by peroxidase-coupled secondary antibodies (Sigma, St Louis, MO, USA). Proteins were visualized by enhanced chemiluminescence (PIERCE, Rockford, USA).

Generation of His-GFP-Annexin-V and purification. His-GFPAnnexin-V (GFPAn-V) was generated by subcloning the GFP-Annexin-V cDNA ${ }^{39}$ into the Xhol/BamH1 sites of pET15b (Novagen, Darmstadt, Germany). The construct was transfected into the Escherichia coli strain BL21(DE3) and protein expression was induced with $1 \mathrm{mM} \mathrm{IPTG}$ at $25^{\circ} \mathrm{C}$ overnight. Bacteria were lysed in TBS-T $(0.1 \%$ Tween), lysosyme $(0.8 \mathrm{mg} / \mathrm{ml})$, protease inhibitor cocktail (Roche; Penzberg; Germany), and Triton X-100 (1\%). The protein was purified by a HisBind ${ }^{\mathbb{R}}$ purification kit (Novagen) as provided by the manufacturer.

GFPAn-V- and PI-stainings. After growing cells to confluency on $12 \mathrm{~mm}$ glass coverslips, stressed, and unstressed cells were directly stained without prior washing (to avoid losing detached cells) with $3 \mu \mathrm{g} / \mathrm{ml}$ GFPAn-V and $2.5 \mu \mathrm{g} / \mathrm{ml}$ propidium iodide (PI, Sigma) in Annexin-V binding buffer ( $10 \mathrm{mM}$ Hepes/ $\mathrm{NaOH}, \mathrm{pH}$ $7.4,140 \mathrm{mM} \mathrm{NaCl}, 2.5 \mathrm{mM} \mathrm{CaCl}_{2}$ ) and subsequently fixed in $4 \%$ paraformaldehyde (PFA) containing $2 \mu \mathrm{g} / \mathrm{ml}$ of the Hoechst 33342 stain (Molecular Probes, Carlsbad, CA, USA). The coverslips were viewed under an Eclipse TE300 microscope (Nikon) and pictures were taken with a Photometrics, Roper Scientific Inc., Germany, Cool Snap EZ camera at a magnification of $\times 1000$. For flow cytometry, media, and cells from untreated and treated samples were collected by trypsinization, stained with $3 \mu \mathrm{g} / \mathrm{ml}$ GFPAn-V and $2.5 \mu \mathrm{g} / \mathrm{ml} \mathrm{PI}$ in Annexin-V binding buffer and incubated at room temperature for $15 \mathrm{~min}$, diluted in $200 \mathrm{ml}$ of AnnexinV binding buffer, and read on a BD LSR flow cytometer (BD Biosciences, San Jose, CA, USA). Data were processed with CellQuest Pro (BD Biosciences).

Mitochondrial cytochrome $c$ release. Rat 6 cells were fixed on coverslips in $4 \%$ PFA and permeabilized for 5 min with $0.05 \%$ saponin and 15 min in ice-cold acetone. Cells were washed in PBS and incubated with primary anti-cytochrome $c$ antibodies (BD) at a dilution of 1:200 in PBA (PBS with $1 \%$ bovine albumin). After incubation with secondary FITC-conjugated antibodies (Molecular Probes) 1:200 in PBA, cells were fixed in $4 \%$ PFA containing $2 \mu \mathrm{g} / \mathrm{ml}$ of Hoechst 33342 stain.

GFP ${ }^{\mathrm{u}}$ transfection. By appending a short degron sequence, $\mathrm{CL}^{12}$ to the $\mathrm{C}$ terminus of GFP, the protein is constitutively degraded by the proteasome; this fusion protein is referred to as GFP ${ }^{13}$ Rat 6 fibroblasts $\left(5 \times 10^{6}\right)$ were mixed gently with $3 \mu \mathrm{g}$ of GFP ${ }^{\mathrm{u}}$ DNA, ${ }^{13}$ electroporated with a Nucleofector Kit Number $\mathrm{V}$ for cell lines according to the manual (Amaxa; Köln; Germany). Electroporated cells were re-suspended in culture medium, seeded onto 12-well culture dishes at a density of $2.7 \times 10^{5}$ cells per well, and recovered overnight at $37^{\circ} \mathrm{C}$ before drug treatment.

Statistical analysis. Data passed the d'Agostino and Pearson omnibus normality test (K2) test for normal distribution and are represented as mean and S.E.M. Groups were compared by one-way ANOVA, followed by Tukey test $(P<0.0001)$, using the Prism software package (version 4, GraphPad Prism).

Acknowledgements. We thank Ron Kopito for the GFP ${ }^{u}$ construct, Joel Ernst for the GFPAn-V, Benjamin F. Cravatt for the active site directed inhibitor FP-Biotin, Harvey L. Ozer for the ts20 and the H38-5 cell lines, Thomas Reinheckel for discussion of mass spectrometry results, Karen Poksay for technical help, and Andreas Strasser for kindly providing us with antibodies for caspase-2, Bcl-w and several BH3 proteins. This work was supported by the Swiss National Science Foundation (L.E.), the Larry L. Hillblom Foundation (D.T.M.), and by NS33376 from the National Institutes of Health.

1. Menendez-Benito V, Verhoef LG, Masucci MG, Dantuma NP. Endoplasmic reticulum stress compromises the ubiquitin-proteasome system. Hum Mol Genet 2005; 14: 2787-2799

2. Wickner W, Schekman R. Protein translocation across biological membranes. Science 2005; 310: 1452-1456. 
3. Lee MC, Miller EA, Goldberg J, Orci L, Schekman R. Bi-directional protein transport between the ER and Golgi. Annu Rev Cell Dev Biol 2004; 20: 87-123.

4. Kisselev AF, Goldberg AL. Proteasome inhibitors: from research tools to drug candidates. Chem Biol 2001; 8: 739-758.

5. Romisch K. Endoplasmic reticulum-associated degradation. Annu Rev Cell Dev Biol 2005; 21: $435-456$.

6. Bernales S, Papa FR, Walter P. Intracellular Signaling by the Unfolded Protein Response. Annu Rev Cell Dev Biol 2006 Jul 5.

7. Ferri KF, Kroemer G. Organelle-specific initiation of cell death pathways. Nat Cell Biol 2001; 3: E255-E263.

8. Hacki J, Egger L, Monney L, Conus S, Rosse T, Fellay I et al. Apoptotic crosstalk between the endoplasmic reticulum and mitochondria controlled by Bcl-2. Oncogene 2000; 19 : 2286-2295.

9. Ruiz-Vela A, Opferman JT, Cheng EH, Korsmeyer SJ. Proapoptotic BAX and BAK contro multiple initiator caspases. EMBO Rep 2005; 6: 379-385.

10. Taylor RC, Adrain C, Martin SJ. Proteases, proteasomes and apoptosis: breaking Ub is hard to do. Cell Death Differ 2005; 12: 1213-1217.

11. Egger L, Schneider J, Rheme C, Tapernoux M, Hacki J, Borner C. Serine proteases mediate apoptosis-like cell death and phagocytosis under caspase-inhibiting conditions. Cell Death Differ 2003; 10: 1188-1203.

12. Gilon $T$, Chomsky $O$, Kulka RG. Degradation signals for ubiquitin system proteolysis in Saccharomyces cerevisiae. EMBO J 1998; 17: 2759-2766.

13. Bence NF, Sampat RM, Kopito RR. Impairment of the ubiquitin-proteasome system by protein aggregation. Science 2001; 292: 1552-1555.

14. Kisselev AF, Akopian TN, Castillo V, Goldberg AL. Proteasome active sites allosterically regulate each other, suggesting a cyclical bite-chew mechanism for protein breakdown. Mol Cell 1999; 4: 395-402.

15. McCormack TA, Cruikshank AA, Grenier L, Melandri FD, Nunes SL, Plamondon L et al. Kinetic studies of the branched chain amino acid preferring peptidase activity of the $20 \mathrm{~S}$ proteasome: development of a continuous assay and inhibition by tripeptide aldehydes and clasto-lactacystin beta-lactone. Biochemistry 1998; 37: 7792-7800.

16. Nakagawa T, Zhu H, Morishima N, Li E, Xu J, Yankner BA et al. Caspase-12 mediates endoplasmic-reticulum-specific apoptosis and cytotoxicity by amyloid-beta. Nature 2000 403: 98-103.

17. Zinszner $\mathrm{H}$, Kuroda M, Wang X, Batchvarova N, Lightfoot RT, Remotti $\mathrm{H}$ et al. CHOP is implicated in programmed cell death in response to impaired function of the endoplasmic reticulum. Genes Dev 1998; 12: 982-995.

18. Hideshima T, Richardson P, Chauhan D, Palombella VJ, Elliott PJ, Adams $\mathrm{J}$ et al. The proteasome inhibitor PS-341 inhibits growth, induces apoptosis, and overcomes drug resistance in human multiple myeloma cells. Cancer Res 2001; 61: 3071-3076.

19. Drexler HC. Activation of the cell death program by inhibition of proteasome function. Proc Natl Acad Sci USA 1997; 94: 855-860.

20. Lee AH, Iwakoshi NN, Anderson KC, Glimcher LH. Proteasome inhibitors disrupt the unfolded protein response in myeloma cells. Proc Natl Acad Sci USA 2003; 100: 9946-9951.

21. Fribley $A$, Zeng $Q$, Wang $C Y$. Proteasome inhibitor PS-341 induces apoptosis through induction of endoplasmic reticulum stress-reactive oxygen species in head and neck squamous cell carcinoma cells. Mol Cell Biol 2004; 24: 9695-9704.

22. Obeng EA, Carlson LM, Gutman DM, Harrington Jr WJ, Lee KP, Boise LH. Proteasome inhibitors induce a terminal unfolded protein response in multiple myeloma cells. Blood 2006; 107: 4907-4916.
23. Knepper-Nicolai B, Savill J, Brown SB. Constitutive apoptosis in human neutrophils requires synergy between calpains and the proteasome downstream of caspases. $J$ Biol Chem 1998; 273: 30530-30536.

24. Sadoul R, Fernandez PA, Quiquerez AL, Martinou I, Maki M, Schroter M et al. Involvement of the proteasome in the programmed cell death of NGF-deprived sympathetic neurons. EMBO J 1996; 15: 3845-3852.

25. Nijhawan D, Fang M, Traer E, Zhong Q, Gao W, Du F et al. Elimination of Mcl-1 is required for the initiation of apoptosis following ultraviolet irradiation. Genes Dev 2003; 17 $1475-1486$

26. Tonomura N, McLaughlin K, Grimm L, Goldsby RA, Osborne BA. Glucocorticoid-induced apoptosis of thymocytes: requirement of proteasome-dependent mitochondrial activity. $J$ Immunol 2003; 170: 2469-2478.

27. Canu N, Barbato C, Ciotti MT, Serafino A, Dus L, Calissano P. Proteasome involvement and accumulation of ubiquitinated proteins in cerebellar granule neurons undergoing apoptosis. J Neurosci 2000; 20: 589-599.

28. Zhai $Q$, Wang J, Kim A, Liu Q, Watts R, Hoopfer $E$ et al. Involvement of the ubiquitin-proteasome system in the early stages of wallerian degeneration. Neuron 2003 39: $217-225$

29. Zhong Q, Gao W, Du F, Wang X. Mule/ARF-BP1, a BH3-only E3 ubiquitin ligase, catalyzes the polyubiquitination of $\mathrm{Mcl}-1$ and regulates apoptosis. Cell 2005; 121 1085-1095.

30. Srivastava RK, Mi QS, Hardwick JM, Longo DL. Deletion of the loop region of Bcl-2 completely blocks paclitaxel-induced apoptosis. Proc Natl Acad Sci USA 1999; 96: $3775-3780$

31. Deng X, Gao F, Flagg T, May Jr WS. Mono- and multisite phosphorylation enhances Bcl2's antiapoptotic function and inhibition of cell cycle entry functions. Proc Natl Acad Sci USA 2004; 101: 153-158.

32. Domina AM, Vrana JA, Gregory MA, Hann SR, Craig RW. MCL1 is phosphorylated in the PEST region and stabilized upon ERK activation in viable cells, and at additional sites with cytotoxic okadaic acid or taxol. Oncogene 2004; 23: 5301-5315.

33. Breitschopf K, Haendeler J, Malchow P, Zeiher AM, Dimmeler S. Posttranslational modification of $\mathrm{Bcl}-2$ facilitates its proteasome-dependent degradation: molecular characterization of the involved signaling pathway. Mol Cell Biol 2000; 20 $1886-1896$

34. Dimmeler S, Breitschopf K, Haendeler J, Zeiher AM. Dephosphorylation targets Bcl-2 fo ubiquitin-dependent degradation: a link between the apoptosome and the proteasome pathway. J Exp Med 1999; 189: 1815-1822.

35. Kucharczak JF, Simmons MJ, Duckett CS, Gelinas C. Constitutive proteasomemediated turnover of $\mathrm{Bfl}-1 / \mathrm{A} 1$ and its processing in response to TNF recepto activation in FL5.12 pro-B cells convert it into a prodeath factor. Cell Death Differ 2005 12: $1225-1239$

36. McCullough KD, Martindale JL, Klotz LO, Aw TY, Holbrook NJ. Gadd153 sensitizes cells to endoplasmic reticulum stress by down-regulating $\mathrm{Bcl} 2$ and perturbing the cellular redox state. Mol Cell Biol 2001; 21: 1249-1259.

37. Rao RV, Ellerby HM, Bredesen DE. Coupling endoplasmic reticulum stress to the cell death program. Cell Death Differ 2004; 11: 372-380.

38. Chowdary DR, Dermody JJ, Jha KK, Ozer HL. Accumulation of $\mathrm{p} 53$ in a mutant cell line defective in the ubiquitin pathway. Mol Cell Biol 1994; 14: 1997-2003.

39. Ernst JD, Yang L, Rosales JL, Broaddus VC. Preparation and characterization of an endogenously fluorescent annexin for detection of apoptotic cells. Anal Biochem 1998 260: 18-23.

\section{Supplementary Information accompanies the paper on Cell Death and Differentiations website (http://www.nature.com/cdd)}

